\title{
COMPARATIVE EVALUATION OF THE EFFECTS OF FLUORIDE VARNISH, PROPOLIS BASED CHITOSAN VARNISH AND SALVADORAPERSICA VARNISH ON STREPTOCOCCUS MUTANS AND LACTOBACILLI COUNT
}

\author{
Reda Mohamed ElSayed *, Samy Youssef El-Bayoumy **, Ibrahim Farouk Barakat ${ }^{* * *}$
}

\begin{abstract}
Objective: of this study to evaluat the effects of fluoride varnish, propolis based chitosan varnish and salvadorapersica varnish on streptococcus mutans and lactobacilli count. Subjects \& Methods: The sample size wsa estimated to be 48 randomly selected Egyptian children were divided into 4 equal groups: Group A: Fluor protector (F varnish) $(\mathrm{n}=12)$. Group B: Propolis-based chitosan varnish $(\mathrm{n}=12)$. Group C: Salvadorapersica chitosan varnish $(\mathrm{n}=12)$. Group D: control group Patients without varnish $(n=12)$. After baseline plaque samples were obtained from each of the subject, varnish application procedure was carried out for each of the subject in all four groups. Before application of varnish, oral prophylaxis was carried out for subjects. The teeth was then isolated. Approximately $0.1 \mathrm{~mL}$ of the designated varnish will be applied to all the teeth of subjects in all the three groups. Varnish was allowed to dry. The varnish was applied once every 3 days for all the three groups in the same manner as above. The follow-up plaque samples from all the three varnish groups was taken at the end of $48 \mathrm{~h}$, at $1 \mathrm{~m}$, at the end of $3 \mathrm{~m}$ and at the end of $6 \mathrm{~m}$ and assessed for bacterial counts. Result: There was a statistically significant difference in the count of streptococcus mutans and lactobacillus between all groups in which the highest bacterial count was found in Group D group followed by Group A and Group B, while the least bacterial count was found in Group C. Conclusions: All varnishes containing natural products had a significant antibacterial effect against S. mutans and lactobacillus bacteria compared to patient without varnish application.
\end{abstract}

Key words: Propolis, Miswak, Chitosan, Dental Varnish, lactobacillus, Streptococcus mutans:

\section{INTRODUCTION}

Dental caries is a biofilm-induced oral disease with Streptococcus.mutans playing a key role in the development of virulent cariogenic biofilms Thus, decreasing the bacterial burden of the oral cavity is one of the fundamental biological goals in preventing dental caries ${ }^{(1)}$.

Adhesion and colonization of oral microbes on tooth surfaces and restorations is considered crucial in the development of secondary caries and periodontal disease. Streptococcus mutans is the main microorganism that initiates dental caries and lactobacillus are important in further caries development especially in the dentin ${ }^{(2)}$.
Dental varnishes can be applied easily and quickly, and can deliver an active agent as fluoride or chlorhexidine to the teeth safely and in high concentration.

The most important anti-caries effect of fluoride results from its local action on the tooth/plaque interface, through promotion of remineralization and minimizing demineralization. It also prevents acid production by S.mutans ${ }^{(3)}$.

Due to the increase of antibiotic resistance and side effects of some antimicrobials on one hand, and the safety, availability and relatively low costs of natural products on the other hand, a variety of

\footnotetext{
* Pedodontics and Puplic Health Department, Al Azhar University Assuit Branch

** Professor of Pedodontics and Oral Health Faculty of Dental Medicine, Boys, Cairo Al-Azhar University

*** Assistant Professor of Pedodontics and Oral Health Faculty of Dental Medicine, Boys, Cairo Al-Azhar University
} 
natural products have been assessed for caries prevention as well as incorporated into dental products.

Propolis, a natural beehive product, is a complex resinous material that inhibits S.mutans growth and ability to adhere to tooth surfaces. The minimum inhibitory concentration (MIC) of ethanolic extract of propolis (EEP) on S.mutans varies from 25-100 ug/ $\mathrm{mL}$. A minimum bactericidal concentration (MBC) of more than $1600 \mathrm{ug} / \mathrm{mL}$ was reported. Propolis also reduced human dental plaque accumulation and its insoluble external polysaccharide content ${ }^{(4)}$.

Miswak obtained from the roots or twigs of Arak (Salvadora persica) tree, which is found in many Asian and African countries, is one of many plants that have antimicrobial potential, anti-tumor, antiinflammatory and wound healing ${ }^{(5)}$.

Chitosan is a natural polymer obtained by alkaline hydrolysis of chitin. Chitosan has antitumor, wound-healing, mucoadhesive, and antimicrobial activities. Its positive charge facilitates its adhesion to bacterial cell walls giving bacteriostatic or bacteriocidal activities to the material ${ }^{(6)}$. Thus, the present study sought to assess the effects of fluoride varnish, propolis based chitosan varnish and salvadorapersica varnish on streptococcus mutans and lactobacilli count.

The aim of this study was directed to compare the effects of fluoride varnishes, propolis-based chitosan varnish and Salvadorapersica varnish on Streptococcus mutans and lactobacilli count.

\section{SUBJECTS AND METHODS}

Study design: prospective, interventional study.

The study was carried out 48 randomly selected Egyptian children from the Pedodontics Outpatient Clinic, Faculty of Dental Medicine, Al-Azhar University with age was ranged from 6 to 8 years. The children and their parents were informed about the purpose of the study and an informed consent document prior to participation was signed.

\section{Inclusion criteria:}

1. DMFT/deft $>1$.

2. Healthy children free of any systemic diseases.

3. Written informed consent from the parents/ guardians.

4. The agreement to comply with the study visits and procedures.

5. The patients' ages range from (6-8) years.

\section{Exclusion criteria:}

1. Patient with relevant medical history.

2. Handicapped/mentally challenged children.

3. Those taking xylitol chewing gums/undergone any fluoride treatment which could influence the conduct of the study.

4. Those who had received antimicrobial therapy in the previous 3 months.

5. Children with any intraoral device/developmental defect.

6. Poor cooperation reported by guardians of subjects.

\section{Children were divided into 4 equal groups:}

- Group A: Fluor protector (F varnish) $(\mathrm{n}=12)$.

- Group B: Propolis-based chitosan varnish $(\mathrm{n}=12)$.

- Group C: Salvadorapersica chitosan varnish $(\mathrm{n}=12)$

- Group D: control group Patients without $\operatorname{varnish}(n=12)$.

\section{Baseline information and treatment:}

Oral hygiene practice and 24-h diet history of all the subjects were recorded using a questionnaire form, and oral hygiene instructions, diet counseling, and fluoridated toothpaste was given during the period of study. Routine dental treatment such 
as extractions and restoration of all open carious lesions will be carried out prior to commencement of the study.

\section{Varnish application procedure:}

After baseline plaque samples were obtained from each of the subject, varnish application procedure was carried out for each of the subject in all four groups. Before application of varnish, oral prophylaxis was carried out for subjects.

The teeth was then isolated with cotton rolls and saliva ejector and dried with gentle blow of air for $30 \mathrm{~s}$ using three-way air syringe. Approximately $0.1 \mathrm{~mL}$ of the designated varnish will be applied to all the teeth of subjects in all the three groups.

Varnish was allowed to dry, and after one minute, the cotton rolls will be removed. Subjects in all the three groups was instructed not to rinse their mouth, not to drink or eat anything for three hours, and not to brush till the next day ${ }^{(7)}$.

\section{Follow up:}

The varnish was applied once every 3 days for all the three groups in the same manner as above. The follow-up plaque samples from all the three varnish groups was taken at the end of $48 \mathrm{~h}$, at one month, at the end of $3 \mathrm{~m}$ and at the end of $6 \mathrm{~m}$ and assessed for MS counts in the same manner as described before. During the study period, the subjects was asked to report any adverse effects noticed by them immediately to the parents and the investigator ${ }^{\left({ }^{8}\right)}$.

\section{Evaluation methods:}

\section{Microbiological analysis:}

Plaque sampling were carried out at baseline, at $48 \mathrm{~h}$ after the varnish application, at the end of 1 month and at the end of the 3 months. The subjects will be informed to refrain from oral hygiene procedures for $24 \mathrm{~h}$, prior to plaque sampling. The adherent saliva will be removed using water spray and then air-dried. Plaque will be collected using a wooden toothpick from smooth surfaces (by streaking on buccal and lingual surfaces from occlusal to gingival one-third) of all the molars of the selected subjects and transferred to small plastic vials containing thioglycollate transport media. All the above-mentioned procedures will be performed by a single investigator with proper aseptic measures ${ }^{(9,10)}$.

Tip of the wooden toothpick will be cut off and transported to microbiological laboratory containing thioglycollate transport media on the same day.

Samples were preserved in a tube containing $9 \mathrm{ml}$ thioglycolate broth medium as transfer medium to keep the viability of the aerobic and anaerobic micro-organisms under complete aseptic condition. All specimens were transported as soon as possible to microbiological lab at Microbiology Department, Faculty of Medicine, Girls, Al-Azhar University for culture on selective media. For determining streptococcus mutans count, mitis salivarius with bacitracin agar was used according to the manufacturer's instructions. Normal saline containing the specimens was dispersed by agitation in a vortex mixer at maximum speed for $60 \mathrm{sec}-$ onds. Homogenized specimens were serially diluted down to $10^{6}$ in sterile normal saline. The inoculated plates were then placed in anaerobic jar containing gas pack and incubated for 3 days at $37^{\circ} \mathrm{C}$. The same procedure was used to determine Lactobacillus count but using selective De Man, Rogosa and Sharpe (MRS) agar.

\section{RESULTS}

\section{Streptococcus mutans results:-}

\section{Comparison between all groups regarding strep- tococcus count:}

There was a statistically significant difference in the count of streptococcus mutans and lactobacillus between all groups in which The highest bacterial count was found in (Group D) group followed by (Group A) and (Group B) groups, while the least bacterial count was found in (Group C) group. 
TABLE (1) The mean, standard deviation (SD) values of LOG 10 of Bacterial count of different Streptococcus mutants groups.

\begin{tabular}{|c|c|c|c|c|c|c|c|c|c|}
\hline \multirow{3}{*}{ Variables } & \multicolumn{9}{|c|}{ Streptococcus mutants } \\
\hline & \multicolumn{2}{|c|}{ Group A } & \multicolumn{2}{|c|}{ Group B } & \multicolumn{2}{|c|}{ Group C } & \multicolumn{2}{|c|}{ Group D } & \multirow{2}{*}{ p-value } \\
\hline & Mean & SD & Mean & SD & Mean & SD & Mean & SD & \\
\hline Pre & 3.388 & 0.031 & 3.349 & 0.056 & 3.322 & 0.012 & 3.366 & 0.016 & $0.086 n s$ \\
\hline 48 hrs. & 3.366 & 0.027 & 3.333 & 0.037 & 3.277 & 0.040 & 3.347 & 0.028 & $0.016 *$ \\
\hline $1 \mathrm{~m}$ & 3.232 & 0.032 & 3.228 & 0.012 & 3.165 & 0.063 & 3.306 & 0.019 & $0.002 *$ \\
\hline $3 \mathrm{~m}$ & 3.113 & 0.039 & 3.057 & 0.066 & 3.039 & 0.055 & 3.278 & 0.026 & $<0.001 *$ \\
\hline $6 \mathrm{~m}$ & 3.067 & 0.030 & 3.016 & 0.039 & 2.994 & 0.046 & 3.303 & 0.022 & $<0.001 *$ \\
\hline p-value & \multicolumn{2}{|c|}{$<0.001 *$} & \multicolumn{2}{|c|}{$0.002 *$} & \multicolumn{2}{|c|}{$0.001 *$} & \multicolumn{2}{|c|}{$0.001 *$} & \\
\hline
\end{tabular}

*; significant $(p<0.05) \quad n s ;$ non-significant $(p>0.05)$

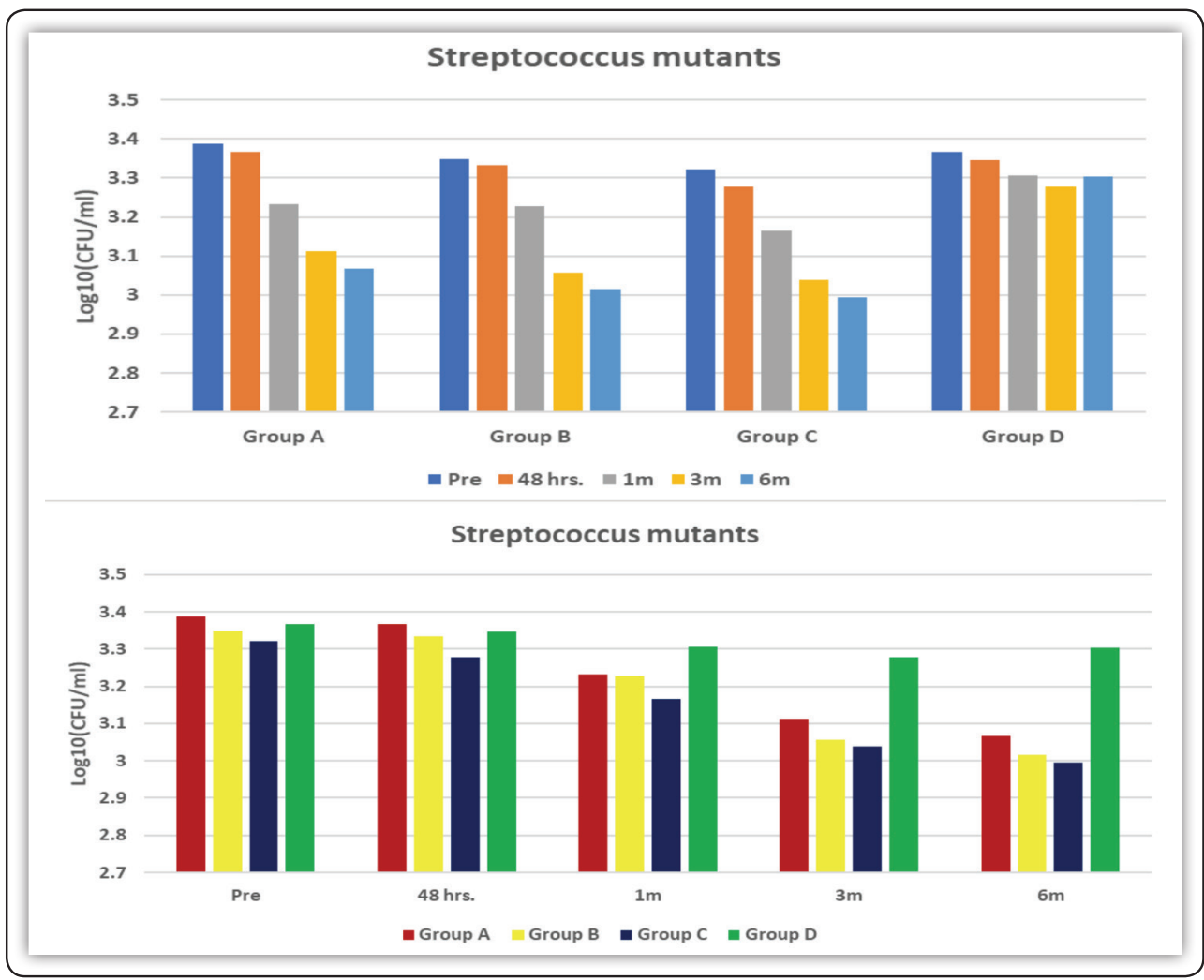

FIG (1) Bar charts representing antibacterial activity of Streptococcus mutants for different groups 


\section{Lactobacillus results:}

\section{Comparison between all groups regarding strepto- coccus count:}

There was a statistically significant difference in the count of streptococcus mutans and lactobacillus between all groups in which The highest bacterial count was found in (Group D) group followed by (Group A) and (Group B) groups, while the least bacterial count was found in (Group C) group.

TABLE (2): The mean, standard deviation (SD) values of LOG 10 of Bacterial count of different Lactobacillus groups.

\begin{tabular}{|c|c|c|c|c|c|c|c|c|c|}
\hline \multirow{3}{*}{ Variables } & \multicolumn{9}{|c|}{ Lactobacillus } \\
\hline & \multicolumn{2}{|c|}{ Group A } & \multicolumn{2}{|c|}{ Group B } & \multicolumn{2}{|c|}{ Group C } & \multicolumn{2}{|c|}{ Group D } & \multirow{2}{*}{$\mathrm{p}$-value } \\
\hline & Mean & SD & Mean & SD & Mean & SD & Mean & SD & \\
\hline Pre & 3.595 & 0.045 & 3.556 & 0.028 & 3.606 & 0.014 & 3.546 & 0.032 & $0.054 \mathrm{~ns}$ \\
\hline $48 \mathrm{hrs}$. & 3.570 & 0.037 & 3.531 & 0.030 & 3.587 & 0.011 & 3.523 & 0.027 & $0.019^{*}$ \\
\hline $1 \mathrm{~m}$ & 3.459 & 0.026 & 3.387 & 0.029 & 3.442 & 0.032 & 3.510 & 0.029 & $0.001 *$ \\
\hline $3 \mathrm{~m}$ & 3.403 & 0.052 & 3.364 & 0.037 & 3.366 & 0.016 & 3.506 & 0.017 & $<0.001 *$ \\
\hline $6 \mathrm{~m}$ & 3.358 & 0.046 & 3.339 & 0.031 & 3.327 & 0.006 & 3.515 & 0.019 & $<0.001^{*}$ \\
\hline p-value & \multicolumn{2}{|c|}{$<0.001 *$} & \multicolumn{2}{|c|}{$<0.001 *$} & \multicolumn{2}{|c|}{$<0.001 *$} & \multicolumn{2}{|c|}{$0.016 *$} & \\
\hline
\end{tabular}

*; significant $(p<0.05) \quad n s ;$ non-significant $(p>0.05)$

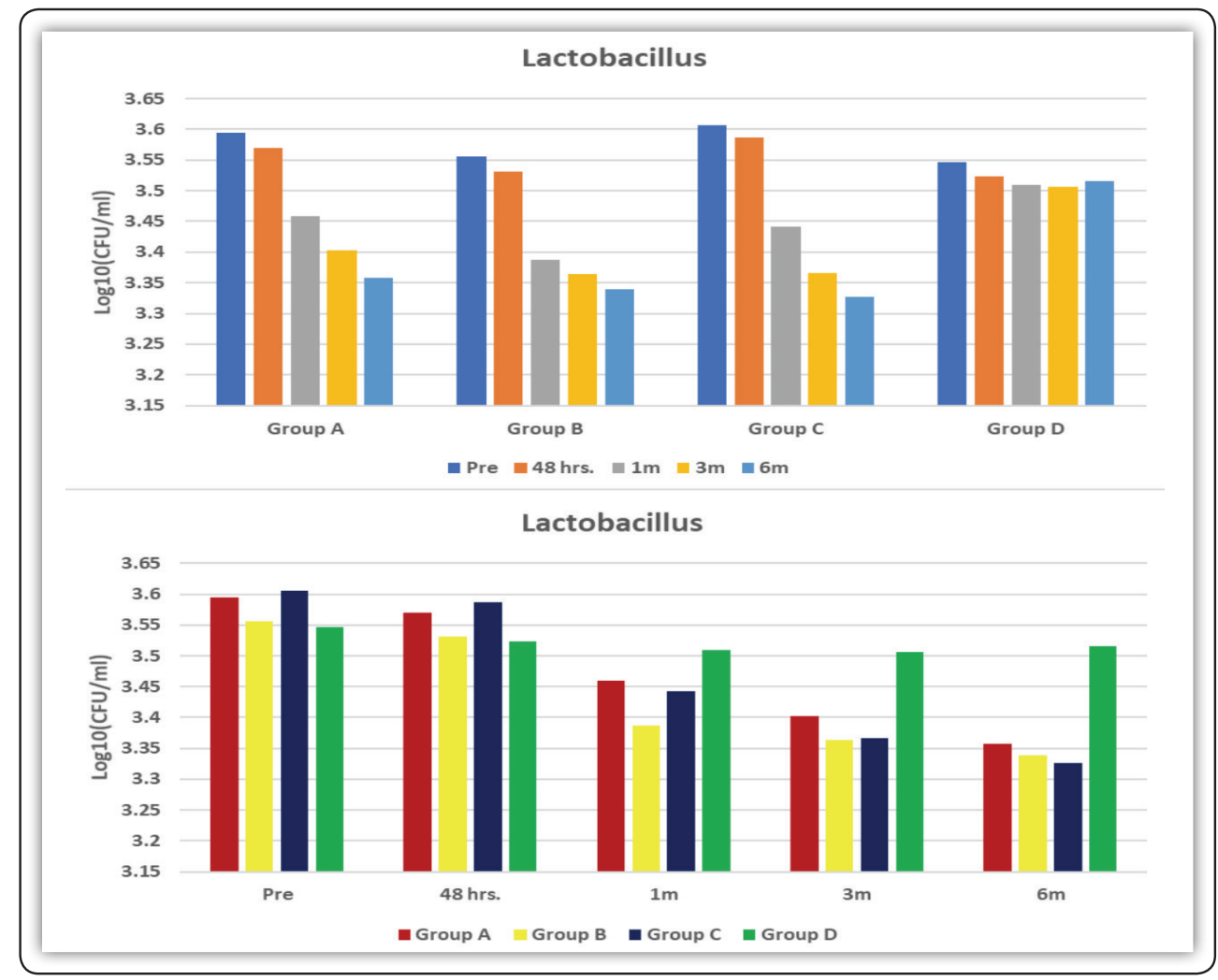

FIG (2) Bar chart representing antibacterial activity of Lactobacillus for different groups 


\section{DISCUSSION}

In the present study we used varnishes to preserve and protect the young permanent molar from caries because the young permanent molar recently erupted in which normal physiological apical root closure has not occurred . Normal physiological root closure of permanent teeth may take 2-3 years after eruption. Young permanent teeth are in developmental stage in children from 6 years of age until mid-teens. Human tooth with immature apex is a developing organ. The proliferation and differentiation of various cells are activated especially in the apical region of the young tooth to make it complete. Developing teeth are essential for development and growth of alveolar process and periodontal ligament ${ }^{(11)}$.

In the present study we used rubber dam which it is able to isolate one or more teeth. it provide a clean and dry operating field away from substances such as saliva and blood. This is important for dental procedures as the bonding ability of the varnish to the tooth. If the environment is contaminated leading to poor bonding of the materials, the success and longevity of the varnish is shortened ${ }^{(12)}$.

The analysis of newly developed dental materials with regard to the accumulation of dental plaque is commonly used in dental material science ${ }^{(13)}$. S. mutans and lactobacillus have been chosen in this study as a representative oral bacterium as it is considered as one of the most abundant microorganisms in the oral cavity ${ }^{(14)}$. S. mutans is the principle microbe causing dental caries also, the initial stage of for developing secondary caries is due to the capability of S. mutans to adhere to the surface of the restoration and lactobacillus are important in further caries development especially in the dentin ${ }^{(15)}$. In this study, swabs were collected from the occlusal, lingual and buccal surfaces as they harbor more microbes and more prone to caries ${ }^{(16)}$.

Patients were carefully selected according to the inclusion criteria in order to standardize the clinical situation. Patients were free of systemic diseases which may lead to increase the microbial adhesion and have an effect over the gingival health ${ }^{(17)}$. Patients had no history of antibiotic intake for the past 2 weeks because composition of normal commercial bacteria may be disrupted by the frequent use of broad spectrum antibiotics ${ }^{(18)}$. Patients had no history of fluoride treatment for the past 2 weeks as fluoride significantly influence the bacterial composition of plaque, also higher levels of fluoride could eliminate susceptible microorganisms and modify the plaque ecosystem ${ }^{(19)}$.

Sodium Fluoride varnishes is used in the present study because it considered as the best varnishes for caries prevention and ions remineralization their use fail to meet the esthetic demands of the patient and the parents because is its poor esthetic effect. A yellow film of varnish remains on the teeth for several hours after application unless it is removed by brushing; in addition, there is a temporary discoloration of teeth after varnish application ${ }^{(20)}$. While the majority of patients find the presence of varnish on their teeth acceptable, it is the authors' experience that some patients dislike its presence as a thin film on their teeth or they find the taste of the varnish objectionable. Gagging and swallowing are unusual ${ }^{(21)}$.

In the present study we used the most popular sodium Fluoride varnish is Duraphat offers the theoretical advantage of prolonged contact time, acting as a slow-releasing reservoir to prevent the immediate loss of fluoride after application ${ }^{(22)}$. Moreover the varnish can be applied quickly and easily and sets rapidly on teeth. Application of fluoride varnish to four first molars may take less than half a minute. Warren et al reported that both patients and operators prefer fluoride varnish to fluoride gel $^{(23)}$. More importantly, Bowden's 1998 study reported that fluoride varnishes are safe for young children compared with other types of topical fluoride treatments (such as gels or rinses) or other caries management methods (24). Fluoride varnishes offer effective caries prevention, ease of application, and safety ${ }^{(25)}$. 
A systematic review of caries management methods by Bader et al reported that fluoride varnish was "fair" at preventing dental caries, while the evidence for other methods, including sucrose-free gum and combined chlorhexidine fluoride methods, was incomplete. In addition, a recent review by Petersson found an average preventive fraction of $30 \%(0-69 \%)$ of fluoride varnish in children. Fluoride varnishes have gained attention in terms of public health dentistry and it is likely that they will become the most common form of topical fluorides applied by dentists $\left({ }^{26)}\right.$.

In a previous study different fluoride containing varnishes showed varying degrees of antimicrobial activity which was not correlated to the fluoride content or fluoride released from the varnishes. In the same study combining a varnish containing $1 \%$ fluoride with a $1 \%$ containing chlorhexidine varnish produced a synergistic effect on S. mutans and S. sobrinus biofilms compared to each varnish alone ${ }^{(27)}$.

In the present study we used, propolis based chitosan varnish. Propolis has low toxicity and has several biological activities that strengthens its employment in healthcare. Several studies have demonstrated the antimicrobial activity of propolis extracts against cariogenic microorganisms (28). Chitosan is a biocompatible and biodegradable polymer. Its positive charge combines to the cell wall of bacteria, promoting a bactericidal and bacteriostatic property to this material ${ }^{(29)}$. These properties, coupled with the ability to form a film and adhere to the tooth, make chitosan an ideal base for sustained drug release ${ }^{(30)}$.

In the present study we used Miswak(Salvadora persica) which have antimicrobial potential ${ }^{(31)}$. Antimicrobial, anti-tumor, anti-inflammatory, and wound healing properties of miswak extract have been linked to its content of tannic acid, alkaloids, eucalyptol, sulphur compounds, benzylisothiocynate, and benzyl nitrate. Its aqueous extract was also reported to have high calcium, but low fluoride content $^{(32)}$. Its extracts possess plaque inhibiting and antimicrobial properties against cariogenic bacteria by inhibiting their growth and acid production ${ }^{(33,34)}$ The unique complexity of the Miswak phytochemicals and miner-als, along with its long fibres, gives it an advantage asa tool for oral and dental health care through providingall of the necessary means of mechanical and chemicalcleaning and maintaining healthy teeth and gums. The release of chemicals and minerals from Miswak at the time of usage stimulates saliva production and buffers its $\mathrm{pH}^{(35)}$.

Regarding to results of microbial adhesion to teeth, in the present study there was no significant difference in the count of streptococcus mutans and lactobacillus between group A (Sodium fluoride varnish), group B(Propolis-based chitosan varnish) and group C (Salvadorapersica chitosan varnish). While The highest bacterial count was found in group D (Patients without varnish). These results may be due to chemical composition of this materials which have antimicrobial potential.

These results in agreement with (Franca JR. et al 2014) who evaluate the Propolis-based chitosan varnish: drug delivery, controlled release and antimicrobial activity against oral pathogen bacteria which use three formulations of propolis based chitosan varnish (PCV) containing different concentrations that show the formulations presented a tooth surface adherence and were able to form films very fast on bovine tooth surface. Also, propolisbased chitosan varnishes have shown antimicrobial activity against all oral pathogen bacteria ${ }^{(36)}$.

Also these results supported by (Balto $\mathrm{H}$. et al 2017) who evaluate Effectiveness of Salvadora persica extracts against common oral pathogens that Ethanol and hexane extracts of S. persica were found to exhibit maximum antimicrobial activity against $\mathrm{S}$. mutans $\mathrm{S}$. sanguis and $\mathrm{S}$. salivarius at high concentrations ${ }^{(37)}$.

Although propolis and miswak containing varnishes had similar antibacterial effects, miswak may be a better option for clinical use as propolis based chitosan varnish made a dark brown coating that may not be clinically acceptable ${ }^{(38)}$. 


\section{CONCLUSIONS}

From the results of the present study, the following conclusions could be drawn:

1. All varnishes containing natural products had a significant antibacterial effect against $\mathrm{S}$. mutans and lactobacillus bacteria compared to patient without varnish application.

2. Probolis based chitosan varnish and salvadorapersica varnish better than Sodium flourid varnish in the aspect of prevention of plaque adhesion.

3. Propolis based chitosan varnish produce a dark brown coating that may not be clinically acceptable.

\section{REFERENCES}

1. Jeon JG, Rosalen PL, Falsetta ML, Koo H. Natural products in caries research: current (limited) knowledge, challenges and future perspective. Caries Res 2011;45:243-6.

2. Byun R, Nadkarni M \& Chour L. Quantitative analysis of diverse lactobacillus species present in advanced dental caries. J Clin Microbiol. 2004; 42(7): 128-36.

3. Marinho VCC, Worthington HV, Walsh T, Clarkson JE. Fluoride varnishes for preventing dental caries in children and adolescents. Cochrane Database Syst Rev. 2013; 7: 1-29.

4. Duarte S, Koo H, Bowen HW, Hayacibara MF, Cury JA, Ikegaki M, et al. Effect of a Novel Type of Propolis and Its Chemical Fractions on Glucosyltransferases and on Growth and Adherence of Mutans Streptococci. Biol Pharm Bull. 2003;26(4):527-31.

5. Halawany HS. A review on miswak (Salvadora persica) and its effect on various aspects of oral health. Saudi Dent J 2012; 24(2):63-9.

6. Sarwar A, Katas H, and Zin NM. Antibacterial effects of chitosan-tripolyphosphate nanoparticles: impact of particle size molecular weight. J Nanopart Res 2014;16:2517-31 .

7. Sandham HJ, Brown J, Chan KH, Phillips HI, Burgess $\mathrm{RC}$, Stokl AJ. Clinical trials in adults of an antimicrobial varnish for reducing mutans streptococci. J Dent Res. 1991; 70(11):1401-08.

8. Assaf AV, de castro Meneghim C, Zanin L, Tengan C, Pereria AC. Effect of different diagnostic threshold on dental caries calibration- a 12 month evaluation. Community Dent Oral Epidemiol. 2006; 34:213-9.
9. Dawes C. Circadian rhythms in human salivary flow rate and composition. J Physiol. 1972; 220:529-45.

10. Navazesh M. Methods for collecting saliva. Ann N Y Acad Sci. 1993; 694:72-7.

11. Wolfman, N. M., Hattersley, G., Cox, K., Celeste, A. J., Nelson, R., Yamaji, N., et al. J. Clin. Invest. 1997;100: 321-30

12. Cochran, M. A.; Miller, C. H.; Sheldrake, M. A. "The efficacy of the rubber dam as a barrier to the spread of microorganisms during dental treatment". Journal of the American Dental Association. 1989; 119 (1): 141-4.

13. Tanner J, Vallittu P \& Soderling E. Adherence of Streptococcus mutans to an E-glass fiber-reinforced composite and conventional restorative materials used in prosthetic dentistry. J Biomed Mater Res. 2000;49:250-6

14. Kawashima M, Hanada N, Hamada T\& Tagami H. Real-time interaction of oral streptococci with human salivary components. Oral Microbiol Immunol. 2003; 18:220-5.

15. Montanaro L, Campoccia D, Rizzi S, Donati M, Breschi L, Prati C, et al. Evaluation of bacterial adhesion of streptococcus mutans on dental restorative materials. Biomaterials. 2004; 25:457-63.

16. Subramanyam D\& Gurunathan D. Microbial evaluation of plaque on 3M ESPE and kids stainless steel crown in primary molars. Int J Pedod Rehabil. 2016 ;1:60-3.

17. Siudikiene J, Machiulskiene V, Nyvad B, Tenovuo J\& Nedzelskiene I. Dental caries and salivary status in children with type 1 diabetes mellitus, related to the metabolic control of the disease. Eur J Oral Sci. 2006;114:8-14.

18. Fukuda J, Sonis A, Platt O\& Kurth S. Acquisition of mutans streptococci and caries prevalence in pediatric sickle cell anemia patients receiving long-term antibiotic therapy. Pediatr Dent 2005;27:186-90.

19. Kilian M, Larsen J, Fejerskov O\& Thylstrup A. Effects of fluoride on the initial colonization of teeth in vivo. Caries Res. 1979

20. Warren DP, Henson HA, Chan JT. Dental hygienist and patient comparisons of fluoride varnishes to fluoride gels. J Dent Hyg 2000;74:94-101.

21. Blinkhorn A, Davis R. Using fluoride varnish in the practice. Br Dent J 1998;185: 280-1.

22. Ogard B, Seppa L, Rolla G. Professional topical fluoride applications-Clinical efficacy and mechanism of action. Adv Dent Res 1994;8:190-201.

23. Seppa L. Effect of dental plaque on fluoride uptake by enamel from a sodium fluoride varnish in vivo. Caries Res $1983 ; 17: 71-75$. 
24. Bawden JW. Fluoride varnish: A useful new tool for public health dentistry. J Public Health Dent 1998;58:266-9.

25. Seppa L. Efficacy and safety of fluoride varnishes. Compend Contin Educ Dent 1999;20:18-26.

26. Petersson LG, Twetman S. Dahlgren H, Norlund A, Holm AK, Nordenram G, Lagerlof F, Soder B, Kallestal C, Mejare I, Axelsson S, Lingstrom P. Professional fluoride varnish treatment for caries control: A systematic review of clinical trials. Acta Odontol Scand. 2004;62:170-6.

27. Erdem AP, Sepet E, Kulekci G, Trosola SC, Guven Y. Effects of two fluoride varnishes and one fluoride/chlorhexidine varnish on Streptococcus mutans and Streptococcus sorbrinus Biofilm formation in Vitro. Int J Med Sci. 2012;9(2):129-36.

28. Bertolini PF, Biondi Filho O, Pomilio A et al. Antimicrobial capacity of Aloe vera and propolis dentifrice against Streptococcus mutans strains in toothbrushes: an in vitro study. J Appl Oral Sci. 2012; 20: 32-7.

29. T. Uysal, M. D. Akkurt, M. Amasyali et al.Does a chitosan containing dentifrice prevent demineralization around orthodontic brackets. Angle Orthodontist.2011; 81(2):319-25.

30. H. Liu, B. Chen, Z. Mao, and C. Gao.Chitosan nanoparticles for loading of toothpaste actives and adhesion on tooth analogs. Journal of Applied PolymerScience. 2007;106(6):4248-56.

31. Jeon JG, Rosalen PL, Falsetta ML, Koo H. Natural products in caries research. current (limited) knowledge, challenges and future perspective. Caries Res.2011;45:243-63.
32. Halawany HS. A review on miswak (Salvadora persica) and its effect on various aspects of oral health. Saudi Dent J. 2012;24:63-9.

33. Darout IA, Christy AA, Skaug N, Egeberg PK. Identification and quantification of some potentially antimicrobial anionic components in miswak extract. Indian J Pharmacol. 2000;32:11-4.

34. Khalessi AM, Pack AR, Thomson WM, Tompkins GR. An in vivo study of the plaque control efficacy of Persica: a commercially available herbal mouthwash containing extract of Salvadora persica. Int Dent J. 2004;54:279-83.

35. Darmani H, Nusayr T, Al-Hiyasat A. Effects of extracts of miswak and derum on proliferation of Balb/C 3T3 fibroblasts and viability of cariogenic bacteria. Int J Dent Hyg. 2006;4(2):62-6.

36. Franca JR, De Luca MP, Ribeiro TG, Castilho RO, Moreira AN, Santos VR, et al. Propolis-based chitosan varnish: drug delivery, controlled release and antimicrobial activity against oral pathogen bacteria. BMC Compl Altern Med. 2014;14:478-89.

37. Balto H, Al-Sanie I, Al-Beshri S, Aldrees A. Effectiveness of Salvadora persica extracts against common oral pathogens. Saudi Dent J. 2017;29(1):1-6.

38. De Luca M.P., Franca J.R., Macedo F.A., Grenho L., Cortes M.E., Faraco A.A. Propolis varnish: antimicrobial properties against cariogenic bacteria, cytotoxicity, and sustained-release profile. Biomed Res Int. 2014;2014:1-6 